\title{
Synthesis and Characterization of Novel Copolymeric Resveratrol Conjugates
}

\author{
Yan-Jing Ng, ${ }^{1}$ Heather A. E. Benson, ${ }^{1}$ David H. Brown, ${ }^{2}$ and Yan Chen ${ }^{1}$ \\ ${ }^{1}$ School of Pharmacy, CHIRI Biosciences, Curtin University, Bentley, WA 6102, Australia \\ ${ }^{2}$ Department of Chemistry, Curtin University, Bentley, WA 6102, Australia \\ Correspondence should be addressed to Yan Chen; y.chen@curtin.edu.au
}

Received 28 December 2014; Accepted 23 February 2015

Academic Editor: Albert Demonceau

Copyright (c) 2015 Yan-Jing Ng et al. This is an open access article distributed under the Creative Commons Attribution License, which permits unrestricted use, distribution, and reproduction in any medium, provided the original work is properly cited.

\begin{abstract}
Resveratrol (RSV), naturally found in plants, is known to have health benefits and has been proposed as a potential anticancer and cardioprotective drug. However, due to its molecular structure, it undergoes rapid metabolism in the body resulting in low bioavailability. Novel polymeric methoxy-poly(ethylene glycol)-block-poly(e-caprolactone) (mPEG-PCL) RSV conjugates with varying PCL chain lengths have been synthesised and formulated into micelles and/or nanoparticles for preliminary in vitro stability studies. RSV conjugated with mPEG2000-PCL9500 was found to have improved solubility and stability of RSV as compared to RSV alone. The length of the PCL chain was found to affect the micelle formation, hence the stability in physiological buffers and rat plasma.
\end{abstract}

\section{Introduction}

RSV (trans-3, 4',5-trihydroxystilbene, $\mathbf{1}$ ) is a polyphenolic [1] phytoalexin naturally found in plants and major dietary sources including grapes [2], red wine [3], peanuts, and root extracts of Polygonum cuspidatum [4]. It possesses antioxidant, anticancer, antiangiogenic, and anti-inflammatory activity $[5,6]$. However, its poor solubility $(0.03 \mathrm{~g} / \mathrm{L}$ in water) and rapid metabolism in the body have resulted in limited clinical applications [7]. Although the nature of the RSV molecule allows high biological absorption due to its lipophilic nature, its polyphenolic nature leads to an extensive metabolism in vivo resulting in almost no oral bioavailability [8]. Pharmacokinetic studies in Wistar rats showed a halflife of 7.8 minutes following intravenous administration [9] whilst, in a Phase I clinical study on RSV dose escalations and bioavailability in humans, no parent compound and only metabolites were detected in blood as early as 15 minutes postoral dosing [8].

The activity of RSV is highly dependent on its molecular structure. A significant difference in anticancer activity was found when the stereoisomers of RSV (trans and cis) were tested on endothelial GM7373 cells [10]. The position of the hydroxyl group on the stilbene ring also influences the activity and potency of the compound [11]. An alteration to the structure of RSV by the addition or replacement with functional groups can increase or decrease activity [12]. However, research has shown increase in bioavailability and efficacy of RSV in nanocarrier systems such as solid lipid nanoparticles (SLNs) [13], liposomal nanoparticles [14, 15], hydroxypropyl-beta-cyclodextrin (HP- $\beta$-CD) particles [16], nanoemulsions [17], copolymer nanoparticles [18, 19], and chitosan-biotin nanoparticles [20]. In addition, conjugation of various biocompatible materials to RSV has been evaluated for regeneration and mineralization of bone [21], anticancer properties [22], and solubility [23].

Shao et al. [18] showed higher loading capacity and better efficacy against glioma cells when RSV is encapsulated into nanosized amphiphilic mPEG-PCL particles, whereas Tang et al. [24] demonstrated better anticancer activity in polymeric conjugated curcumin, a similar molecular structure to RSV. Previously, we demonstrated that conjugation of RSV to $\mathrm{mPEG}$-poly(lactide) (mPEG-PLA) with an ester linkage reduced RSV metabolism and improved its pharmacokinetic profile [25]. Therefore, there is a need for conjugated RSV formulated into nanocarrier systems in order to possibly increase its activity and overcome its poor solubility for therapeutic application. RSV was conjugated to MPEG-PCL due 
to its different crystalline and hydrophobic nature compared to mPEG-PLA [26] which may influence its nanoparticle formation and in vitro properties. In this paper, a series of novel amphiphilic mPEG-PCL RSV conjugates were synthesized and formulated into micelles and/or nanoparticles. These particles/micelles were then characterised and tested for stability.

\section{Experimental}

2.1. Materials. Methoxy-poly(ethylene glycol) (mPEG) $\left(M_{w}\right.$ 2,000 Da), $\varepsilon$-caprolactone $(\varepsilon$-CL), tin (II) ethylhexanoate, glutaric anhydride, triethylamine, pyrene, and pyridine were obtained from Sigma-Aldrich (Australia). Trans-RSV was purchased from DND PharmaTech Co., Inc., Shanghai, China (99\% purity). (3-Dimethylaminopropyl)- $N^{\prime}$ ethylcarbodiimide hydrochloride (EDC. $\mathrm{HCl})$ was purchased from GL Biochem, Shanghai, China. All materials were used without further purification or modification. Plasma from outbred rats was purchased from the Animal Resources Centre (ARC, Western Australia, Australia) collected in a sodium citrate blood collection tube.

\subsection{Methods}

2.2.1. General. Proton NMR (nuclear magnetic resonance, Bruker, $400 \mathrm{MHz}$, Germany) spectra were obtained using deuterated chloroform $\left(\mathrm{CDCl}_{3}\right)$ or deuterated dimethyl sulfoxide $\left(d_{6}\right.$-DMSO) as a solvent. Peak positions and areas were analysed to determine the degree of polymerization using $\operatorname{TopSpin}^{\text {Tx }}$ v3.2 software and comparing integrals of peaks from the PCL block and PEG block.

Gel permeation chromatography (GPC, Agilent; Santa Clara, CA, USA) with a Jordi Gel DVB organic column $(5 \mu \mathrm{m}, 1000 \AA, 25 \mathrm{~cm} \times 4.6 \mathrm{~mm}$; Bellingham, MA, USA) was used to measure the time-dependent molecular weight changes of mPEG-PCL copolymers. A copolymer solution (approximately $1 \mathrm{mg} / \mathrm{L}$ ) was prepared in tetrahydrofuran (as the mobile phase of GPC) for the measurements. The elution rate of the mobile phase was $1.2 \mathrm{~mL} / \mathrm{min}$ and poly (ethylene glycol) standards in the range of 985-42700 g/mol was used for molecular weight calibration. Detection was by an Agilent model G1362A refractive index detector with a detector cell temperature of $40^{\circ} \mathrm{C}$.

High-performance liquid chromatography (HPLC, Agilent; Santa Clara, CA, USA) with Alltech Apollo C18 column $(150 \times 4.6 \mathrm{~mm}, 5 \mu \mathrm{m}$; Columbia, MA, USA) was used to analyse polymeric RSV conjugates and RSV. Analysis was carried out using a mobile phase gradient of solution A $(0.1 \%$ $\mathrm{v} / \mathrm{v}$ formic acid in acetonitrile) and solution $\mathrm{B}(0.1 \% \mathrm{v} / \mathrm{v}$ formic acid in water). Absorbance was monitored at $307 \mathrm{~nm}$ using a UV detector for RSV and fluorescence was measured at $307 \mathrm{~nm}$ (ex) and $400 \mathrm{~nm}$ (em) using a fluorescence detector for RSV polymeric conjugates. All calculations were carried out using peak areas.

Nanoparticle size and size distribution were determined by photon correlation spectroscopy using a Zetasizer $3000 \mathrm{HS}$ (Malvern Instruments, Malvern, Worcestershire, UK). The measurements were performed at $25^{\circ} \mathrm{C}$ with a detection angle of $90^{\circ}$, and the raw data were subsequently correlated to $\mathrm{Z}$ average mean size using a cumulative analysis by the Zetasizer 3000 HS software package. Each sample was measured 10 times. The zeta potential of particles was determined by laser Doppler anemometry using a Zetasizer 3000HS. For each sample, the mean \pm SD of 3 repeat measurements was established.

2.2.2. Synthesis of mPEG-PCL. mPEG-PCL with varying PCL chain lengths was synthesized under vacuum via ringopening polymerization. For the synthesis of mPEG2000PCL5100, mPEG $(15.2 \mathrm{~g}, 7.6 \mathrm{mmol})$ was used as a macroinitiator and $\varepsilon$-CL $(25.7 \mathrm{~g}, 225 \mathrm{mmol})$ was added as a monomer whereas tin (II) ethylhexanoate (10\% w/w mPEG, $1.5 \mathrm{~g}$ ) was added as a catalyst into a round bottom flask. The reaction mixture was sealed under vacuum and stirred at $150^{\circ} \mathrm{C}$ for $24 \mathrm{~h}$. The reaction mixture was then allowed to cool and minimal amount dichloromethane was added to dissolve the reaction mixture. The flask was resealed and allowed to sit at room temperature for $4 \mathrm{~h}$. Excess ice-cold ether was then added to precipitate the copolymer and the flask was resealed and left in the fridge overnight to allow further precipitation. The precipitate was filtered under vacuum to afford a creamcoloured powder $(39.3 \mathrm{~g}, 72.8 \%), M_{w} 7,100 \mathrm{Da} .{ }^{1} \mathrm{H} \mathrm{NMR}$ $\left(\mathrm{CDCl}_{3}, 400 \mathrm{MHz}\right): \delta 1.3-1.4\left(\mathrm{~m},-\mathrm{C}(=\mathrm{O})-\mathrm{C}_{2} \mathrm{H}_{5} \mathrm{CH}_{2} \mathrm{C}_{2} \mathrm{H}_{5} \mathrm{O}-\right.$ ), $\delta$ 1.6-1.7 (m, - $\left.\mathrm{C}(=\mathrm{O})-\mathrm{CH}_{2} \mathrm{CH}_{2} \mathrm{CH}_{2} \mathrm{CH}_{2} \mathrm{CH}_{2} \mathrm{O}-\right), \delta 2.2$ (t, $\left.-\mathrm{C}(=\mathrm{O})-\mathrm{CH}_{2} \mathrm{CH}_{2} \mathrm{CH}_{2} \mathrm{CH}_{2} \mathrm{CH}_{2} \mathrm{O}-\right), \delta 3.4$ (s, $\left.3 \mathrm{H},-\mathrm{OCH}_{3}\right)$, $\delta 3.6\left(\mathrm{~s},-\mathrm{OCH}_{2} \underline{\mathrm{CH}}_{2} \mathrm{OC}(=\mathrm{O})-\right)$, and $\delta 4.0(\mathrm{t},-\mathrm{C}(=\mathrm{O})-$ $\mathrm{CH}_{2} \mathrm{CH}_{2} \mathrm{CH}_{2} \mathrm{CH}_{2} \overline{\mathrm{C}}_{2} \mathrm{O}-$ ). Varying PCL chain lengths were achieved by adjusting the mPEG: $\varepsilon$-CL $w / w$ feed ratio (Table 1).

2.2.3. Synthesis of the Glutarate Ester of mPEG-PCL (mPEGPCL-glu). mPEG-PCL5100 (5.1 g, $2.6 \mathrm{mmol})$, glutaric anhydride $(1.5 \mathrm{~g}, 13.1 \mathrm{mmol})$, and triethylamine $(0.4 \mathrm{~mL})$ were dissolved in anhydrous toluene in a round bottom flask and stirred under vacuum at $90^{\circ} \mathrm{C}$ for $8 \mathrm{~h}$. The reaction mixture was cooled and dissolved in minimal amount of dichloromethane and allowed to stand at room temperature for $1 \mathrm{~h}$. Excess ice-cold ether was then added to precipitate a cream-coloured product (5.2 g, 100\%). ${ }^{1} \mathrm{H} \mathrm{NMR}\left(\mathrm{CDCl}_{3}\right.$, $400 \mathrm{MHz}): \quad \delta \quad 1.3-1.4 \quad\left(\mathrm{~m},-\mathrm{C}(=\mathrm{O})-\mathrm{C}_{2} \mathrm{H}_{5} \mathrm{CH}_{2} \mathrm{C}_{2} \mathrm{H}_{5} \mathrm{O}-\right)$, $\delta$ 1.6-1.7 (m, $\left.-\mathrm{C}(=\mathrm{O})-\mathrm{CH}_{2} \mathrm{CH}_{2} \mathrm{CH}_{2} \mathrm{CH}_{2} \mathrm{CH}_{2} \mathrm{O}-\right), \delta \quad 1.9$ $\left(\mathrm{m},-\mathrm{OC}(=\mathrm{O})-\mathrm{CH}_{2} \mathrm{CH}_{2} \mathrm{CH}_{2}-\mathrm{C}(=\mathrm{O}) \mathrm{O}-\right), \delta 2.2(\mathrm{t},-\mathrm{C}(=\mathrm{O})-$ $\left.\mathrm{CH}_{2} \mathrm{CH}_{2} \mathrm{CH}_{2} \mathrm{CH}_{2} \mathrm{CH}_{2} \mathrm{O}-\right), \quad \delta \quad 2.3-2.4 \quad(\mathrm{~m}, \quad-\mathrm{OC}(=\mathrm{O})-$ $\left.\mathrm{C}_{2} \mathrm{CH}_{2} \underline{\mathrm{CH}}_{2}-\mathrm{C}(=\mathrm{O}) \mathrm{O}-\right), \quad \delta \quad 3.4 \quad\left(\mathrm{~s}, \quad 3 \mathrm{H}, \quad-\mathrm{OCH}_{3}\right), \quad \delta$ 3.6 (s, $\left.-\mathrm{OCH}_{2} \mathrm{CH}_{2} \mathrm{OC}(=\mathrm{O})-\right)$, and $\delta 4.0(\mathrm{t},-\overline{\mathrm{C}}(=\mathrm{O})-$ $\mathrm{CH}_{2} \mathrm{CH}_{2} \mathrm{CH}_{2} \mathrm{CH}_{2} \underline{\mathrm{CH}}_{2} \mathrm{O}-$ ).

2.2.4. Synthesis of mPEG-PCL RSV Prodrugs (mPEG$P C L-g l u-R S V$ 2). The conjugation was achieved by a carbodiimide coupling reaction. Excess amount of RSV was added to mPEG-PCL5100-glu $(5.3 \mathrm{~g}, 0.7 \mathrm{mmol})$ and EDC. $\mathrm{HCl}(2.6 \mathrm{~g}, 13.5 \mathrm{mmol})$ in pyridine $(20 \mathrm{~mL})$ in a round bottom flask. The reaction mixture was stirred at room temperature in the dark under vacuum for $48 \mathrm{~h}$. The reaction mixture was then dissolved in dichloromethane $(15 \mathrm{~mL})$ and washed once with $0.1 \mathrm{M}$ hydrochloric acid and twice with $10 \%$ copper (II) sulphate aqueous solution diluted five 
TABLE 1: Synthesised copolymers with varying mPEG $: \varepsilon-C L$ w/w feed ratio.

\begin{tabular}{lc}
\hline Copolymer & mPEG $: \varepsilon$-CL w/w feed ratio \\
\hline mPEG2000-CL & 0.075 \\
mPEG2000-PCL300 & 0.143 \\
mPEG2000-PCL550 & 0.282 \\
mPEG2000-PCL900 & 0.571 \\
mPEG2000-PCL1300 & 0.839 \\
mPEG2000-PCL9500 & 3.390 \\
mPEG2000-PCL13000 & 5.080
\end{tabular}<smiles>Oc1ccc(/C=C/c2cc(O)cc(O)c2)cc1</smiles>

SCHEMe 1

times in $0.1 \mathrm{M}$ hydrochloric acid. The organic layer was collected and dried with sodium sulphate and filtered. The filtrate was then precipitated with excess ice-cold ether to afford a brown solid $(0.4 \mathrm{~g}, 7.3 \%)$. ${ }^{1} \mathrm{H}$ NMR $\left(d_{6}\right.$-DMSO, $400 \mathrm{MHz}): \quad \delta \quad 1.3-1.4 \quad\left(\mathrm{~m},-\mathrm{C}(=\mathrm{O})-\mathrm{C}_{2} \mathrm{H}_{5} \mathrm{C}_{2} \mathrm{C}_{2} \mathrm{H}_{5} \mathrm{O}-\right)$, $\delta \quad 1.6-1.7 \quad\left(\mathrm{~m}, \quad-\mathrm{C}(=\mathrm{O})-\mathrm{CH}_{2} \mathrm{CH}_{2} \mathrm{CH}_{2} \mathrm{CH}_{2} \mathrm{CH}_{2} \mathrm{O}-\right), \quad \delta$ $1.9 \quad\left(\mathrm{~m}, \quad-\mathrm{OC}(=\mathrm{O})-\mathrm{CH}_{2} \mathrm{CH}_{2} \mathrm{CH}_{2}-\mathrm{C}(=\mathrm{O}) \mathrm{O}-\right), \quad \delta \quad 2.2$ $\left(\mathrm{t}, \quad-\mathrm{C}(=\mathrm{O})-\mathrm{CH}_{2} \mathrm{CH}_{2} \mathrm{CH}_{2} \mathrm{CH}_{2} \mathrm{CH}_{2} \mathrm{O}-\right), \quad \delta \quad 2.3-2.4 \quad(\mathrm{~m}, \quad-$ $\left.\mathrm{OC}(=\mathrm{O})-\mathrm{CH}_{2} \mathrm{CH}_{2} \mathrm{CH}_{2}-\mathrm{C}(=\mathrm{O}) \mathrm{O}-\right), \delta 3.4\left(\mathrm{~s}, 3 \mathrm{H},-\mathrm{OCH}_{3}\right)$, $\delta \quad 3.6 \quad\left(\mathrm{~s}, \quad-\mathrm{OCH}_{2} \mathrm{CH}_{2} \mathrm{OC}(=\mathrm{O})-\right), \quad \delta \quad 4.0 \quad(\mathrm{t}, \quad-\mathrm{C}(=\mathrm{O})-$ $\left.\mathrm{CH}_{2} \mathrm{CH}_{2} \mathrm{CH}_{2} \mathrm{CH}_{2} \mathrm{CH}_{2} \mathrm{O}-\right), \delta 6.1(\mathrm{~s}, 1 \mathrm{H}, \mathrm{H} 4), \delta 6.4(\mathrm{~s}$, $2 \mathrm{H}, \mathrm{H} 2 / 6), \delta 7.0(\mathrm{~s}, 2 \mathrm{H}$, alkenyl $\mathrm{Hs}), \delta 7.1-7.6(\mathrm{dd}, 4 \mathrm{H}$, $\left.\mathrm{H} 2^{\prime} / 3^{\prime} / 5^{\prime} / 6^{\prime}\right)$, and $\delta 9.6$ (s, $\left.2 \mathrm{H},-\mathrm{OH}\right)$ (Scheme 1 ).

2.2.5. Preparation and Characterisation of Conjugate Micelles and/or Nanoparticles. RSV conjugates micelles were prepared by self-assembly and a solvent diffusion method. mPEG2000-glu-RSV was prepared by self-assembly in MilliQ water and then characterised. Other copolymer conjugates were dissolved in organic solvent $(5 \mathrm{mg} / \mathrm{mL})$ and dispersed using an ultrasonic water bath. The organic phase was added to known amounts of MilliQ water and the organic phase was evaporated by bubbling inert nitrogen through. MilliQ water was added to make up to desired concentration. Size and zeta potential of micelles were then measured and subsequently, the micelles were subjected to stability studies.

2.2.6. Stability of $m P E G-P C L-R S V$ Conjugates in Physiological Buffers. Micelle stocks of $50 \mathrm{mg} / \mathrm{mL}(3.5-21.5 \mathrm{mM})$ were diluted five times into acetate buffer $\mathrm{pH} 4.5$ and phosphate buffer pH7.2. Aliquots were divided into Eppendorf tubes for each time point to avoid evaporation and exposure to light. All samples were then incubated at $37^{\circ} \mathrm{C}$ in the dark. At each time point, an aliquot of micelles in each physiological buffer was diluted with $50: 50 \mathrm{v} / \mathrm{v}$ acetonitrile: water for HPLC
TABLE 2: Copolymer yields and molecular weight comparisons between NMR and GPC.

\begin{tabular}{lccc}
\hline Copolymer & Yield (\%) & NMR & GPC \\
\hline mPEG2000-CL & 99.5 & 110 & 160 \\
mPEG2000-PCL300 & 96.9 & 300 & 310 \\
mPEG2000-PCL550 & 95.6 & 500 & 540 \\
mPEG2000-PCL900 & 95.4 & 1200 & 900 \\
mPEG2000-PCL1300 & 98.0 & 1700 & 1300 \\
mPEG2000-PCL5100 & 72.8 & 5700 & 5100 \\
mPEG2000-PCL9500 & 71.9 & 10700 & 9530 \\
mPEG2000-PCL13000 & 79.4 & 12100 & 12930 \\
\hline
\end{tabular}

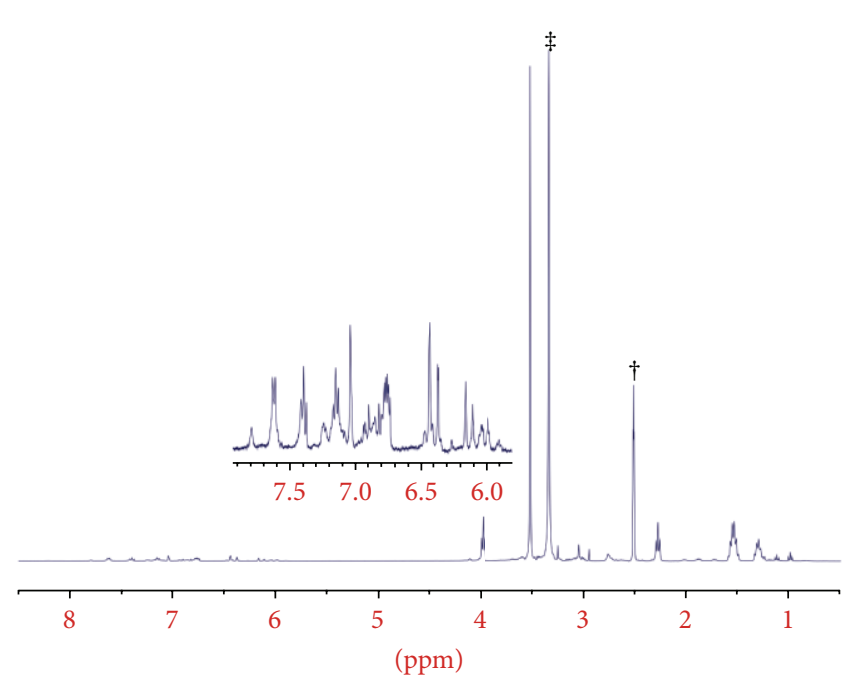

FIGURE 1: ${ }^{1} \mathrm{H}$ NMR spectra $(400 \mathrm{MHz})$ of synthesised mPEG-PCLglu-RSV in $d_{6}$-DMSO. Key: $\dagger=d_{6}$-DMSO, $\ddagger=\mathrm{H}_{2} \mathrm{O}$.

analysis. Peak areas of conjugates of each time point were analysed and data was presented as a percentage change in concentration over time.

2.2.7. Stability of mPEG-PCL-RSV Conjugates in Rat Plasma. The stability of the ester linkages in the conjugates was assessed against the plasma esterases in rat plasma. $10 \mathrm{mg} / \mathrm{mL}$ $(0.7-4.3 \mathrm{mM})$ conjugate micelles were incubated in rat plasma at $37^{\circ} \mathrm{C}$ in the dark. Aliquots of plasma sample $(100 \mu \mathrm{L})$ were prepared for each time point to avoid evaporation. At each time point, an aliquot of plasma was diluted ten times with cold acetonitrile to precipitate plasma proteins. The mixture was centrifuged at $10,000 \mathrm{rpm}$ for 5 minutes. The supernatant was then diluted with $50: 50 \mathrm{v} / \mathrm{v}$ acetonitrile: water and analysed by HPLC. Peak areas of conjugates of each time point were analysed and data was presented as a percentage decrease over time.

\section{Results and Discussion}

3.1. Syntheses of Polymeric RSV Conjugates. Both PEG and PCL are known to be biocompatible and biodegradable [27] and hence would be suitable for the purpose of our 


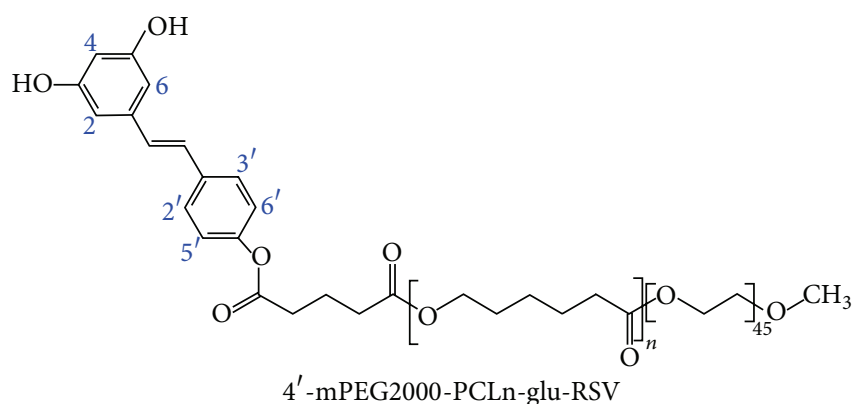

SCHEME 2

TABLE 3: Polymeric conjugate micelles and nanoparticles size and zeta potential.

\begin{tabular}{lccc}
\hline Polymeric conjugate & Size $(\mathrm{nm})$ & Polydispersity index & Zeta potential $(\mathrm{mV})$ \\
\hline mPEG2000-glu-RSV & $369.2 \pm 11.3$ & $0.21 \pm 0.05$ & $3.7 \pm 1.6$ \\
mPEG2000-CL-glu-RSV & $226.2 \pm 16.8$ & 1 & $0.4 \pm 1.6$ \\
mPEG2000-PCL300-glu-RSV & $128.2 \pm 28.4$ & $0.9 \pm 0.096$ & $4.2 \pm 1.6$ \\
mPEG2000-PCL550-glu-RSV & $462.8 \pm 55.8$ & 1 & $2.5 \pm 45.2$ \\
mPEG2000-PCL1300-glu-RSV & $471.1 \pm 16.1$ & $0.475 \pm 0.37$ & $4.2 \pm 1.6$ \\
mPEG2000-PCL5100-glu-RSV & $657.5 \pm 53.2$ & $0.875 \pm 0.217$ & $24.8 \pm 6.3$ \\
mPEG2000-PCL9500-glu-RSV & $57.8 \pm 0.2$ & $0.409 \pm 0.008$ & $3.4 \pm 1.6$ \\
mPEG2000-PCL13000-glu-RSV & $218.4 \pm 0.6$ & $0.138 \pm 0.066$ & $5.6 \pm 1.4$ \\
\hline
\end{tabular}

work. The syntheses of all copolymers were straight-forward and gave high yields (>80\%); however, the synthesis of mPEG-PCL with higher PCL chain lengths produced lower yields (Table 2). The molecular weight of PCL was determined by NMR and GPC by comparison with the known molecular weight of PEG. The degree of polymerization of the PCL was calculated by comparing integral intensity of characteristic resonance of the PCL at $2.2 \mathrm{ppm}\left(-\mathrm{C}\left(=\mathrm{O}-\mathrm{CH}_{2}\right)\right.$ and the PEG resonance at $3.6 \mathrm{ppm}\left(-\mathrm{OCH}_{2} \mathrm{CH}_{2}-\right)$ in the ${ }^{1} \mathrm{H}$ NMR spectrum. The molecular weight of copolymers was determined against the PEG standards calibration curve by GPC analysis. Results from GPC were found to be consistent with ${ }^{1} \mathrm{H}$ NMR data (Table 2).

Using the various PCL chain lengths of mPEG-PCL copolymers, RSV was conjugated with a glutarate ester linkage. The aliphatic ester linkage is hydrolysable which allows the RSV moiety to be released during in vivo use [21]. The glutarification of the copolymers was confirmed by comparing integral intensity of characteristic resonance at $1.9 \mathrm{ppm}$ $\left(-\mathrm{OC}(=\mathrm{O})-\mathrm{CH}_{2} \mathrm{CH}_{2} \mathrm{CH}_{2}-\mathrm{C}(=\mathrm{O}) \mathrm{O}-\right)$ and $2.3-2.4 \mathrm{ppm}$ ($\left.\mathrm{OC}(=\mathrm{O})-\mathrm{CH}_{2} \mathrm{CH}_{2} \mathrm{CH}_{2}-\mathrm{C}(=\mathrm{O}) \mathrm{O}-\right)$ and $\mathrm{PEG}$ resonance at $3.6 \mathrm{ppm}\left(-\mathrm{OCH}_{2} \underline{\mathrm{CH}}_{2}-\right.$ ). The NMR analysis (Figure 1) of conjugates indicated the product is a mixture of conjugates $4^{\prime}$ mPEG-PCL-glu-RSV (about 45\%), 3-mPEG-PCL-glu-RSV (about 18\%), and unconjugated RSV (37\%) (Scheme 2). Since HPLC analysis was able to separate and quantify free RSV and polymeric conjugate, further purification was not performed.

\subsection{Characterisation of Polymeric RSV Conjugate Micelles.}

Table 3 reveals the size and polydispersity index of all polymeric conjugate micelles prepared by self-assembly and solvent diffusion method.
Micelles and/or nanoparticles were of submicron size; however, there was no correlation between PCL chain length and the size of the micelles and/or nanoparticles. This may be due to the effect of the PCL chain length on the hydrophiliclipophilic balance of the conjugate, hence, the formation of micelle and/or nanoparticles. Low magnitude zeta potential is expected as there is no charged species present with polymers and drug. With the right hydrophilic-lipophilic balance, the conjugate should form polymeric micelles with reasonable stability because of the presence of $\mathrm{mPEG}$ on the surface of polymeric micelles. Most micelles/nanoparticles are found to be unstable after $24 \mathrm{~h}$ observed by aggregation and/or precipitation. These unstable formulations, indicated by large polydispersity index (PDI), may require stabilising agents such as polyvinyl alcohol (PVA) which adsorbs onto the surface of micelles/nanoparticles to prevent their aggregation.

3.3. Stability in Physiological Buffers and Rat Plasma. Table 4 shows the stability of each conjugate in physiological buffers and outbred rat plasma. Stability was tested in rat plasma which contains high levels of carboxylesterase [28] which hydrolyses the ester linkage in the RSV conjugates. The final column shows the half-life $\left(t_{1 / 2}\right)$ of each conjugate in rat plasma. The half-life of RSV is known to be 7.8 minutes in Wistar rats [9]. The conjugate micelle with PCL chain length of $9500 \mathrm{Da}$ showed the best stability in plasma compared to others and slightly better than the reported RSV data. Our previous work done on RSV with mPEG-PLA conjugates with succinate linkage showed a different outcome [25]. This suggests that the type polymer, polymer chain length, and linkage are important in determining the chemical stability of the conjugates. 
TABLE 4: Chemical stability of conjugates in physiological buffer at $24 \mathrm{~h}$ and rat plasma.

\begin{tabular}{lcccc}
\hline Polymeric conjugate & MilliQ water & Acetate buffer pH 4.5 & Phosphate buffer pH 7.2 & $t_{1 / 2}$ in rat plasma (min) \\
\hline mPEG2000-glu-RSV & $>65 \%{ }^{*}$ & $>95 \%$ & $>40 \%$ & 3 \\
mPEG2000-CL-glu-RSV & $>80 \%$ & $>95 \%$ & $>95 \%$ & 5 \\
mPEG2000-PCL300-glu-RSV & $\mathrm{n} / \mathrm{d}^{* *}$ & $\mathrm{n} / \mathrm{d}$ & $\mathrm{n} / \mathrm{d}$ & 3 \\
mPEG2000-PCL550-glu-RSV & $\mathrm{n} / \mathrm{d}$ & $\mathrm{n} / \mathrm{d} / \mathrm{d}$ & 3 \\
mPEG2000-PCL1300-glu-RSV & $\mathrm{n} / \mathrm{d}$ & $\mathrm{n} / \mathrm{d}$ & $\mathrm{n} / \mathrm{d}$ & 3.5 \\
mPEG2000-PCL5100-glu-RSV & $>80 \%$ & $>80 \%$ & $>85 \%$ & 4 \\
mPEG2000-PCL9500-glu-RSV & $>95 \%$ & $>90 \%$ & $>90 \%$ & 10 \\
mPEG2000-PCL13000-glu-RSV & $>35 \%$ & $>30 \%$ & $>40 \%$ & 8 \\
\hline
\end{tabular}

${ }^{*}$ Value represents percentage of original concentration at $24 \mathrm{~h} ;{ }^{* *} \mathrm{n} / \mathrm{d}$ : no data.

\section{Conclusion}

Conjugation of RSV to copolymers has overcome the poor solubility issue of RSV by formulating into nanosized particles. In this paper, a series of mPEG-PCL conjugated RSV were synthesized and only one of those with high molecular weight of PCL was found to slightly improve the stability of RSV in plasma as shown in preliminary stability tests. Based on these results and also previous work, further formulation studies and biological evaluation of the conjugates are warranted.

\section{Conflict of Interests}

The authors declare that there is no conflict of interests regarding the publication of this paper.

\section{Acknowledgment}

Yan-Jing Ng would like to thank the financial support from the Australian Postgraduate/Curtin University Postgraduate Scholarship.

\section{References}

[1] Y. Bai, Q.-Q. Mao, J. Qin et al., "Resveratrol induces apoptosis and cell cycle arrest of human T24 bladder cancer cells in vitro and inhibits tumor growth in vivo," Cancer Science, vol. 101, no. 2, pp. 488-493, 2010.

[2] P. W. Mannal, J. A. Alosi, J. G. Schneider, D. E. McDonald, and D. W. McFadden, "Pterostilbene inhibits pancreatic cancer in vitro," Journal of Gastrointestinal Surgery, vol. 14, no. 5, pp. 873879,2010

[3] Y. Bai, Q.-Q. Mao, J. Qin et al., "Resveratrol induces apoptosis and cell cycle arrest of human T24 bladder cancer cells in vitro and inhibits tumor growth in vivo," Cancer Science, vol. 101, no. 2, pp. 488-493, 2010.

[4] J.-N. Lin, V. C.-H. Lin, K.-M. Rau et al., "Resveratrol modulates tumor cell proliferation and protein translation via SIRT1dependent AMPK activation," Journal of Agricultural and Food Chemistry, vol. 58, no. 3, pp. 1584-1592, 2010.

[5] L. Frémont, "Minireview: biological effects of resveratrol," Life Sciences, vol. 66, no. 8, pp. 663-673, 2000.
[6] J. A. Baur and D. A. Sinclair, "Therapeutic potential of resveratrol: the in vivo evidence," Nature Reviews Drug Discovery, vol. 5, no. 6, pp. 493-506, 2006.

[7] G. Singh and R. S. Pai, "Recent advances of resveratrol in nanostructured based delivery systems and in the management of HIV/AIDS," Journal of Controlled Release, vol. 194, pp. 178$188,2014$.

[8] T. Walle, F. Hsieh, M. H. DeLegge, J. E. Oatis Jr., and U. K. Walle, "High absorption but very low bioavailability of oral resveratrol in humans," Drug Metabolism and Disposition, vol. 32, no. 12, pp. 1377-1382, 2004.

[9] C. Yu, Y. Geun Shin, A. Chow et al., "Human, rat, and mouse metabolism of resveratrol," Pharmaceutical Research, vol. 19, no. 12, pp. 1907-1914, 2002.

[10] M. Belleri, D. Ribatti, M. Savio et al., “ $\alpha \mathrm{v} \beta 3$ Integrin-dependent antiangiogenic activity of resveratrol stereoisomers," Molecular Cancer Therapeutics, vol. 7, no. 12, pp. 3761-3770, 2008.

[11] H. J. Lee, J. W. Seo, B. H. Lee, K.-H. Chung, and D. Y. Chi, "Syntheses and radical scavenging activities of resveratrol derivatives," Bioorganic \& Medicinal Chemistry Letters, vol. 14, no. 2, pp. 463-466, 2004.

[12] L.-X. Wang, A. Heredia, H. Song et al., "Resveratrol glucuronides as the metabolites of resveratrol in humans: characterization, synthesis, and anti-HIV activity," Journal of Pharmaceutical Sciences, vol. 93, no. 10, pp. 2448-2457, 2004.

[13] K. Teskač and J. Kristl, “The evidence for solid lipid nanoparticles mediated cell uptake of resveratrol," International Journal of Pharmaceutics, vol. 390, no. 1, pp. 61-69, 2010.

[14] N. K. Narayanan, D. Nargi, C. Randolph, and B. A. Narayanan, "Liposome encapsulation of curcumin and resveratrol in combination reduces prostate cancer incidence in PTEN knockout mice," International Journal of Cancer, vol. 125, no. 1, pp. 1-8, 2009.

[15] J. Lu, S. C. Owen, and M. S. Shoichet, "Stability of self-assembled polymeric micelles in serum," Macromolecules, vol. 44, no. 15, pp. 6002-6008, 2011.

[16] S. Das, H.-S. Lin, P. C. Ho, and K.-Y. Ng, "The impact of aqueous solubility and dose on the pharmacokinetic profiles of resveratrol," Pharmaceutical Research, vol. 25, no. 11, pp. 25932600, 2008.

[17] M. Sessa, R. Tsao, R. Liu, G. Ferrari, and F. Donsì, "Evaluation of the stability and antioxidant activity of nanoencapsulated resveratrol during in vitro digestion," Journal of Agricultural and Food Chemistry, vol. 59, no. 23, pp. 12352-12360, 2011.

[18] J. Shao, X. Li, X. Lu et al., "Enhanced growth inhibition effect of Resveratrol incorporated into biodegradable nanoparticles 
against glioma cells is mediated by the induction of intracellular reactive oxygen species levels," Colloids and Surfaces B: Biointerfaces, vol. 72, no. 1, pp. 40-47, 2009.

[19] W. Guo, A. Li, Z. Jia, Y. Yuan, H. Dai, and H. Li, “Transferrin modified PEG-PLA-resveratrol conjugates: in vitro and in vivo studies for glioma," European Journal of Pharmacology, vol. 718, no. 1-3, pp. 41-47, 2013.

[20] L. Bu, L.-C. Gan, X.-Q. Guo et al., "Trans-resveratrol loaded chitosan nanoparticles modified with biotin and avidin to target hepatic carcinoma," International Journal of Pharmaceutics, vol. 452, no. 1-2, pp. 355-362, 2013.

[21] Y. Li, S. Dnmark, U. Edlund et al., "Resveratrol-conjugated poly-caprolactone facilitates in vitro mineralization and in vivo bone regeneration," Acta Biomaterialia, vol. 7, no. 2, pp. 751-758, 2011.

[22] D. Kumar, K. K. Raj, S. V. Malhotra, and D. S. Rawat, "Synthesis and anticancer activity evaluation of resveratrol-chalcone conjugates," MedChemComm, vol. 5, no. 4, pp. 528-535, 2014.

[23] A. Mattarei, M. Carraro, M. Azzolini, C. Paradisi, M. Zoratti, and L. Biasutto, "New water-soluble carbamate ester derivatives of resveratrol," Molecules, vol. 19, no. 10, pp. 15900-15917, 2014.

[24] H. Tang, C. J. Murphy, B. Zhang et al., "Curcumin polymers as anticancer conjugates," Biomaterials, vol. 31, no. 27, pp. 71397149, 2010.

[25] B. Siddalingappa, H. A. E. Benson, D. H. Brown, K. T. Batty, and Y. Chen, "Stabilization of resveratrol in blood circulation by conjugation to $\mathrm{mPEG}$ and $\mathrm{mPEG}$-PLA polymers: investigation of conjugate linker and polymer composition on stability, metabolism, antioxidant activity and pharmacokinetic profile," PLoS ONE. In press.

[26] V. F. Tamboli, An electrospray ionization mass spectrometric study on reactivity of resveratrol induced by metal ions [Ph.D. thesis], Department of Physics, University of Trento, Trento, Italy, 2012.

[27] S. M. Loverde, M. L. Klein, and D. E. Discher, "Nanoparticle shape improves delivery: rational coarse grain molecular dynamics (rCG-MD) of taxol in worm-like PEG-PCL micelles," Advanced Materials, vol. 24, no. 28, pp. 3823-3830, 2012.

[28] F. G. Bahar, K. Ohura, T. Ogihara, and T. Imai, "Species difference of esterase expression and hydrolase activity in plasma," Journal of Pharmaceutical Sciences, vol. 101, no. 10, pp. 39793988, 2012. 

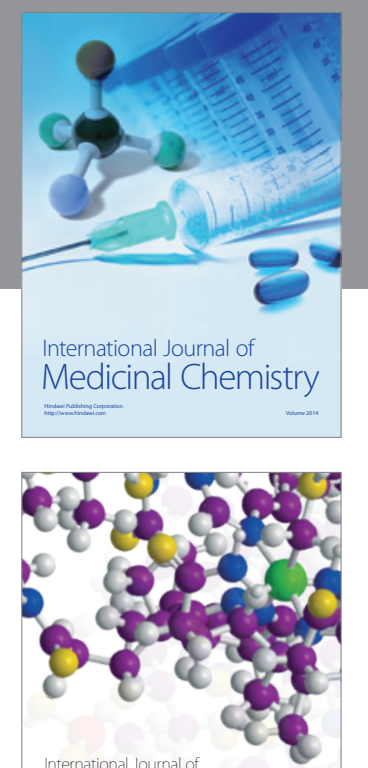

\section{Carbohydrate} Chemistry

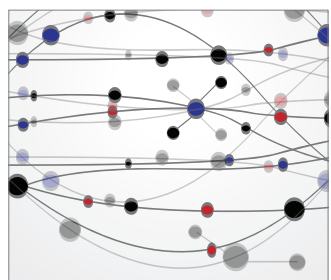

The Scientific World Journal
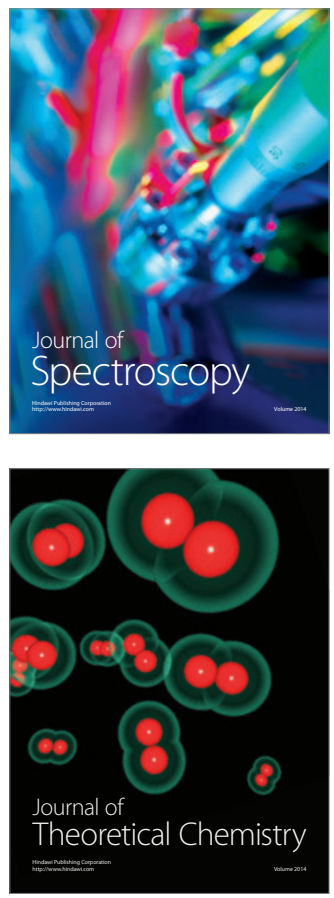
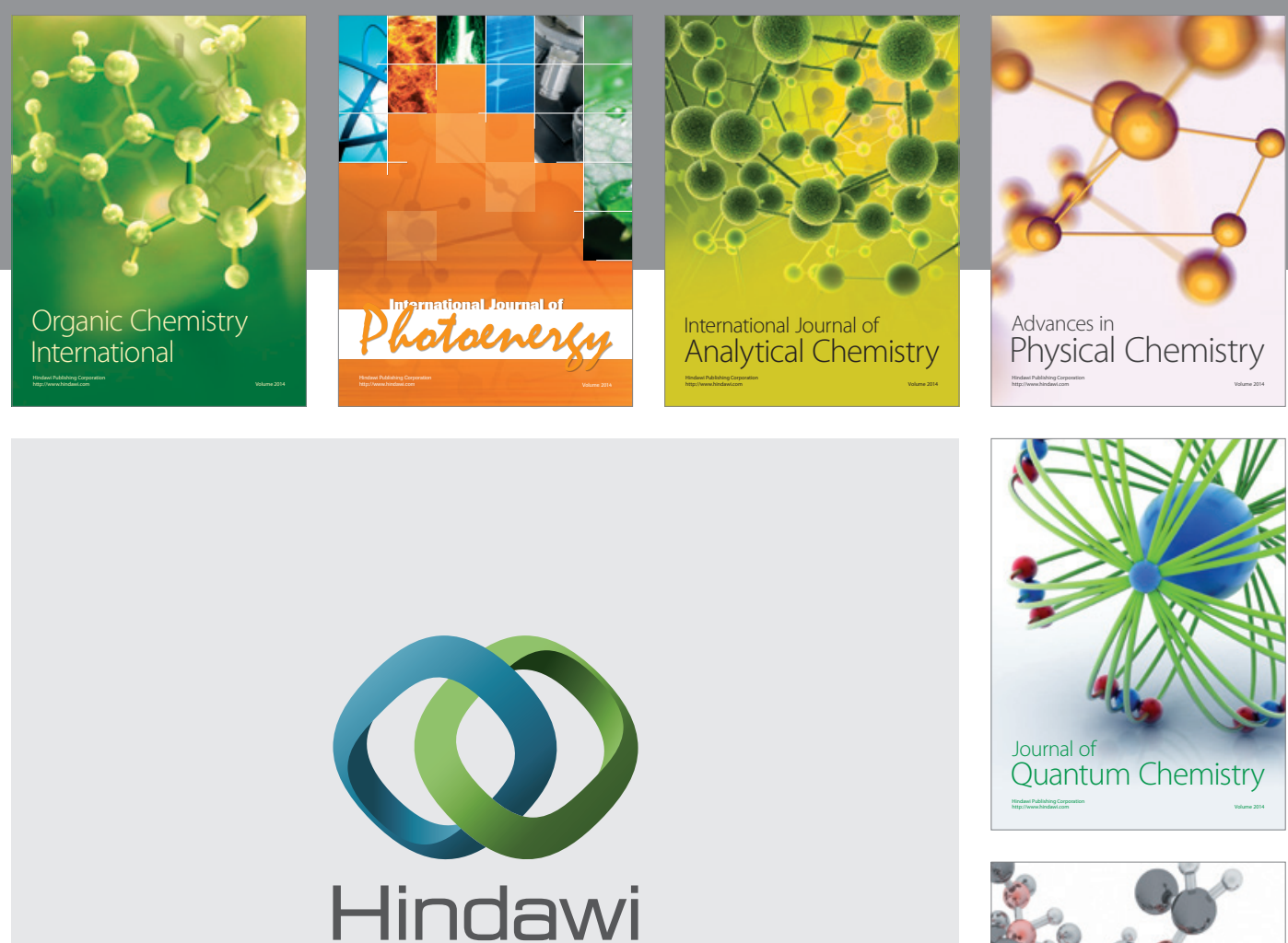

Submit your manuscripts at

http://www.hindawi.com

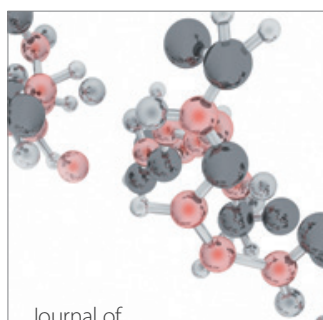

Analytical Methods

in Chemistry

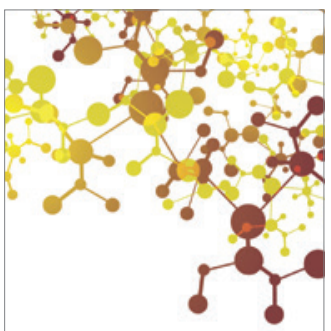

Journal of

Applied Chemistry

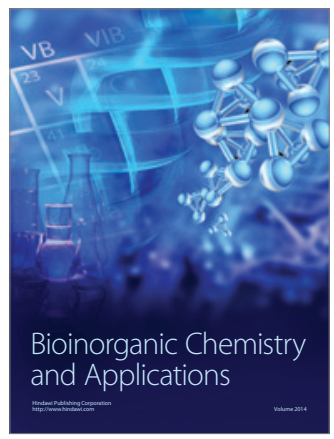

Inorganic Chemistry
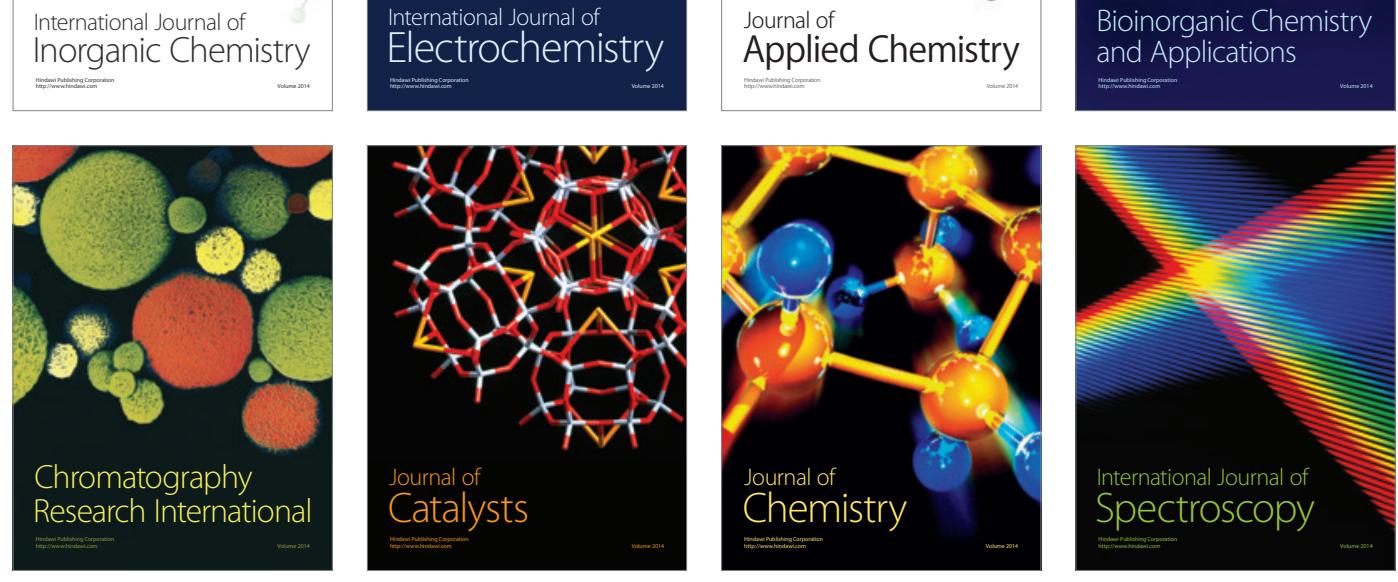